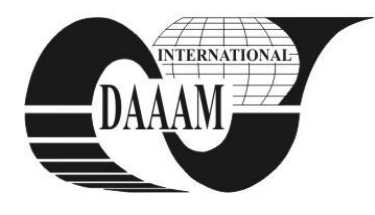

Annals of DAAAM for 2012 \& Proceedings of the 23rd International DAAAM Symposium, Volume 23, No.1, ISSN 2304-1382 ISBN 978-3-901509-91-9, CDROM version, Ed. B. Katalinic, Published by DAAAM International, Vienna, Austria, EU, 2012 Make Harmony between Technology and Nature, and Your Mind will Fly Free as a Bird Annals \& Proceedings of DAAAM International 2012

\title{
MODELING AND SIMULATION OF HYDRAULIC SYSTEMS BY BOND GRAPHS
}

\author{
DAMIC, V[jekoslav]; COHODAR, M[aida] \& KULENOVIC, M[alik]
}

\begin{abstract}
This paper describes a unified approach to modeling and simulation of hydraulic systems using bond graphs. Unlike the others, the causalities are not applied in bond graph settings. This leads that mathematical model is generated in the form of differential algebraic equation (DAEs) and solved as such by suitable solver.

Bond graph model of simple hydraulic system has developed using program BondSim. Several hydraulic components are developed and stored in the program library. They can be reused in modeling of complex systems. Simulation results are compared with ones obtained using MATLAB/Simulink showing good agreement. Proposed methodology can be applied to modeling of systems, which are composed of hydraulic, mechanical and electrical systems. This synergy is widely applied in field of mobile machines, machine tools and other industrial machines and devices where hydraulic systems are often used for power transmission. Bond graphs can be efficiency used in modeling of mechatronics system in whole.

Keywords: bond graphs, hydraulic system, mechatronic system
\end{abstract}

\section{INTRODUCTION}

Integration of electronics and hydraulics components significantly increases the use of hydraulics in industrial machines (machine tools), in mechanizations based on using of robots, mobile cranes and mobile machines, electrohydraulic harvester manipulator, etc [2,14,16,19].

Electrohydraulic systems have high power-to-weight ratio, the ability to rapidly generate very large force, the ability to generate stepless motion and variable speed, easily controllability, etc. On the other hand dynamic of hydraulic systems is highly nonlinear. These are reasons why investigations of electrohydraulic systems continue to attract attention of industry as well as academy community.

Different control techniques are considered in $[1,2,5,9,11,13,16,17]$. An output feedback nonlinear control for position tracking of electrohydraulic system is presented in [11], a Lyapunov-based control algorithm is developed for force tracking control of an electrohydraulic actuator in [1]. An energy based controller, design for under-actuated mechanical system with a hydraulic piston actuator is presented in [17], where the stability of the desired equilibrium of the closed loop system is proven. An adaptive sliding controller for electrohydraulic system, driven by double-rod actuator with nonlinear uncertain parameters is subject of consideration in [9]. To set more economical and quality systems, position control of hydraulic systems is proposed in [5]. Reference [20] proposes Differential Evolution for handling nonlinear constrain functions with boundary limits of variables to find the best values for the unknown parameters of servo hydraulic system with flexible load.

Bond graph technique, based on causalities, is applied in modeling and simulations of hydraulic systems in $[3,4,12,14,15,18]$. A detailed model of a valve controlled hydraulic cylinder using bond graphs was developed in [15] from, as authors pointed out, the first principles and they proposes their work as an educational tool on bond graphs. Bond graph models of basic hydraulic components are given in [18]. Reference [12] presents a study of a wave energy conversion system with hydraulic power take-off using bond graphs. In [3], the hydraulic dynamics of valve-controlled hydraulic cylinder is developed and simulated, and a simplified model of a high frequency hydraulic system is presented. Bond graph library created for Modelica with graphical Dymola support is presented in [4].

This work presents the systematic component model approach based on bond graph technique without consideration of causalities. This provides modeling of complex system, which cannot be analyzed using classical approach, for instance using block diagrams. Model of valve control hydraulic cylinder as open loop system is developed and simulation is performed using software BondSim (developed by the first author of the paper) in this investigation. BondSim generates mathematical model implied by component's structure in the form of differential-algebraic equations (DAEs) and solved them as such. The solver used for solving DAEs is backward differential formula method (BDF) based on variable coefficient [7]. The causality assignment can be conducted as well if applicable.

The main purpose of the paper is to apply the methodology, which can capture basic physics of the problem without going into many details of the hydraulic systems.

It could be interested to investigate possible control strategies in proposed context in the future work. One of directions of the future investigation is to model the other subsystems of complex system in which hydraulic circuit is applied, for instance to model mechanical part manipulator of mobile crane or excavator combining models of mechanical and hydraulic part in unique system. Mechanical part of them can be modeled as flexible using finite element methods, developed in $[6,8]$.

This work is organized as follows. In the second section bond graph models of single and double acting cylinders are presented. Attention of the third section has occupied on development of model of hydraulic system. 
The paper has closed with concluding remarks and recommendation for the future work.

\section{MODELING OF BASIC HYDRAULIC COMPONENTS}

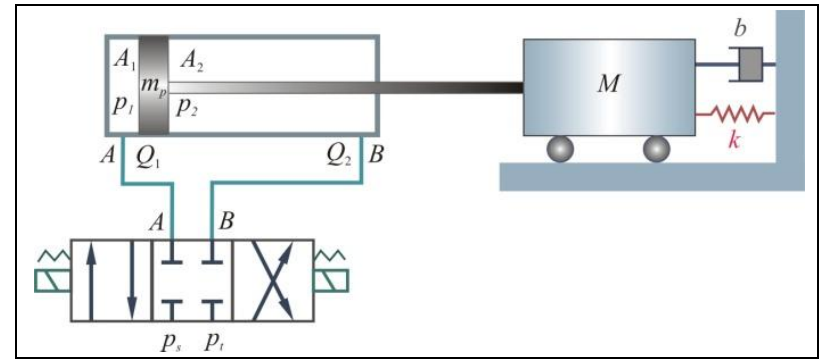

Fig. 1. Schematic diagram of hydraulic system

Modeling of hydraulic components has done according certain assumptions:

a. The valve is symmetrical and the spool of valve is ideal with zero lapping,

b. Hydraulic pump is ideal that means it supplies constant pressure $p_{s}$ for required flow,

c. Pressure of the tank is constant and equal to atmospheric pressure,

d. Dynamic of hydraulic pipe is neglected.

Scheme of double acting hydraulic cylinder controlled by four-way direction valve is shown in Fig.1. Main function of this kind of valve is to direct and distribute flow between cylinder and pump and tank. System is arranged as an open loop. The cylinder drives a load which includes of a mass, viscous friction and spring.

\subsection{Hydraulic cylinder}

Hydraulic cylinders use power of liquid, usually oil, to provide mechanical work - mechanical force and motion.

Functionally, cylinders can produce mechanical work in one and both directions during extending and retracting.

Bond graph model of double acting cylinder is shown in Fig.2.

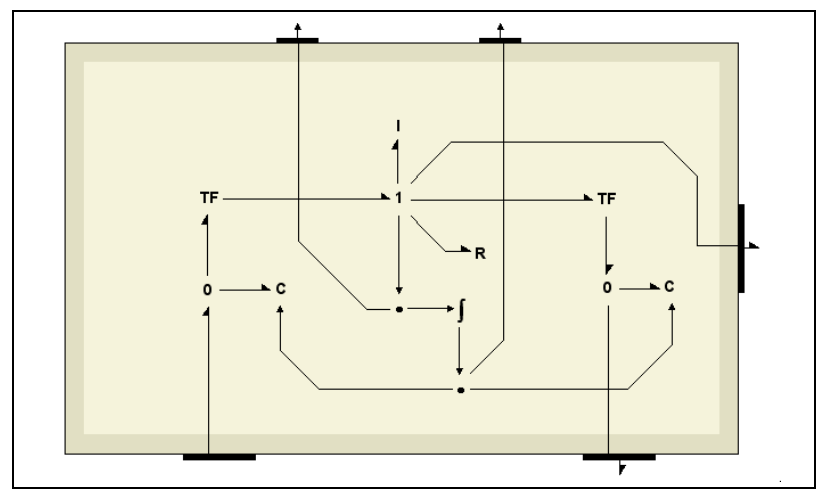

Fig. 2. Bond graph model of double acting cylinder

The cylinder converts fluid power to mechanical giving the force as:

$$
F_{p}=p_{1} A_{1}-p_{2} A_{2}-m_{p} \ddot{x}
$$

where $x$ is the piston displacement, $m_{p}$ is the piston mass, $p_{i}$ is pressure inside chamber $i$ with corresponding section of piston $A_{i}(i=1,2)$. The conversion of the hydraulic to the mechanical power and vice versa is implemented with two transformer components TF.

The power transferred at the ports of the left transformer (knowing that the power is product of variables of effort and flow) is given by:

$$
P=e \cdot f=p_{1} Q_{1}=p_{1} A_{1} v_{1}=F_{1} v_{1},
$$

where $Q_{1}$ is the flow rate to left chamber. It follows that transformer ratio for the left transformer, which defines relationship between efforts or flows $\left(e_{\text {out }}=k_{T R} \cdot e_{i n}\right.$, $\left.f_{\text {out }}=k_{T R} \cdot f_{\text {in }}\right)$ is:

$$
k_{T R_{L}}=A_{1} .
$$

Similarly, the ratio of the right transformer TF is:

$$
k_{T R_{R}}=\frac{1}{A_{2}}
$$

Two lower component power ports (Fig.2) represent ports A and B (Fig.1) - places of cylinder for supply with the oil pressure and its exhaust. Two $\mathrm{C}$ - components represent fluid compressibility in the chambers. The bulk modulus of the oil $\beta$ is used as the measure of compressibility [15]:

$$
\beta=\frac{\Delta p_{i}}{\left(-\frac{\Delta V_{i}}{V_{i}}\right)},
$$

where $\Delta V_{i}$ is change of the volume due to variation of pressure. Chamber volumes $V_{i}(i=1,2)$ are directly in function of piston position $x$ :

$$
\begin{aligned}
& V_{1}=V_{0}+A_{1} x, \\
& V_{2}=V_{0}+A_{2}(L-x) .
\end{aligned}
$$

$V_{0}$ in above equation is initial volume of the chambers and $L$ is the piston stroke.

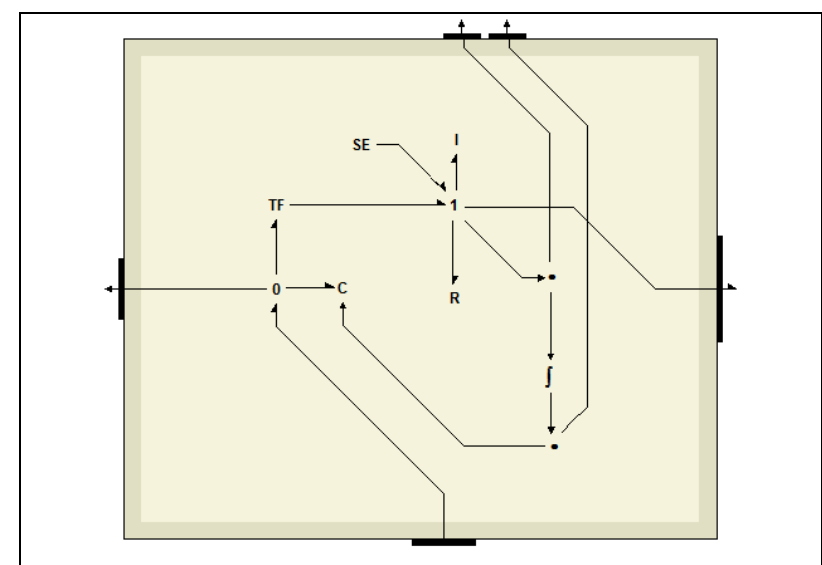

Fig. 3. Bond graph model of single acting cylinder

Following [15], two capacitive elements $C$ can be described by constitutive relations: 


$$
\Delta p_{i}=-\frac{\beta}{V_{i}} \Delta V_{i},
$$

With component $\mathrm{R}$ it is possible to model viscous friction due to piston motion.

In reference [18] this component is used for defining maximum piston stroke. When piston approaches to the end of motion value of resistance becomes very high.

Scheme of single acting cylinder is shown in Fig.3. If cylinder returns to the normal position by an external load it can be mounted in vertical position so return is realized under effect of gravity force that is represented by source effort SE. The oil pressure is fed only to one side of the cylinder.

\subsection{Directional valves}

Main function of directional valve is to direct and distribute flow between consumers, ie. between cylinder and pump and tank from the other side (Fig.1).

The 'way' of valve is modeled by well-known relationship flow-pressure for turbulent flow [13]:

$$
Q_{i}=C_{d} A_{i} \sqrt{\frac{2}{\rho} \Delta p_{i}},(i=1,2)
$$

where $C_{d}$ is the discharge coefficient and $\rho$ is the oil density.

The pressure drop across the valve $\Delta p_{i}$ is $\Delta p_{i}=p_{s}-p_{i},(i=1,2)$ when oil pressure feds to the chamber or $\Delta p_{i}=p_{i}-p_{t},(i=1,2)$ when chamber is connected to the tank.

The pressure drop is represented by $\mathrm{R}$ component in bond graph environment.

\section{NUMERICAL EXAMPLE}

Simple hydraulic system is used as numerical example (similarly to Fig.1).

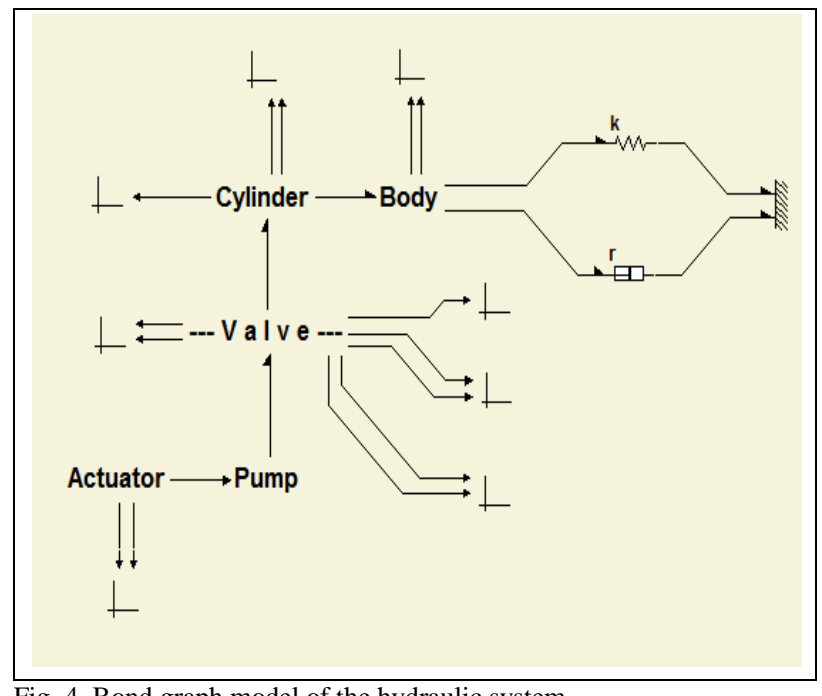

Fig. 4. Bond graph model of the hydraulic system

It consists of single acting cylinder controlled by an electrically operated three way direction valve.

\begin{tabular}{|l|c|c|}
\hline \multicolumn{1}{|c|}{ Parameters } & Unit & Value \\
\hline Mass $(M)$ & $\mathrm{Kg}$ & 40 \\
\hline Spring stiffness coefficient $(k)$ & $\mathrm{N} / \mathrm{m}$ & $1.8 \mathrm{e} 4$ \\
\hline Coefficient of viscous friction $(b)$ & $\mathrm{Ns} / \mathrm{m}$ & 150 \\
\hline Piston section $\left(A_{1}\right)$ & $\mathrm{m}^{2}$ & $13 \mathrm{e}-4$ \\
\hline Piston section $\left(A_{2}\right)$ & $\mathrm{m}^{2}$ & $9.43 \mathrm{e}-4$ \\
\hline Fluid density $(\rho)$ & $\mathrm{kg} / \mathrm{m}^{3}$ & 850 \\
\hline Pressure supply & $\mathrm{Pa}$ & $75 \mathrm{e} 5$ \\
\hline Discharge coefficient $\left(C_{d}\right)$ & & 0.61 \\
\hline Nominal flow rate of valve $(Q)$ & $\mathrm{m}^{3} / \mathrm{s}$ & $1.33 \mathrm{e}-3$ \\
\hline
\end{tabular}

Tab. 1. Material and geometrical parameters of the hydraulic system

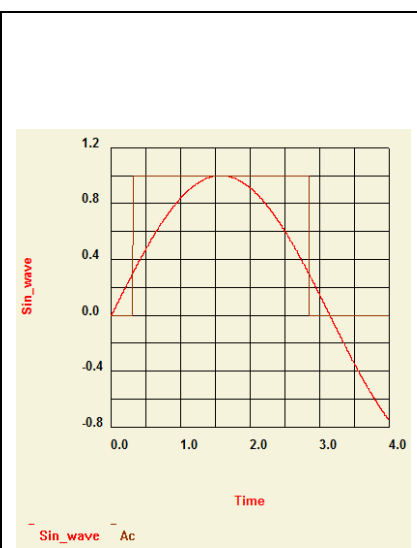

a)

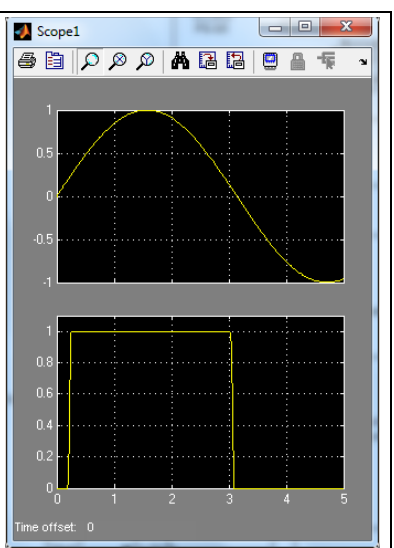

b)
Fig. 5. Time histories of activation signals obtained by a) BondSim; b) MATLAB/Simulink

External load is presented by mass connected by parallel combination of a spring and damper. The piston and mass load are connected using rigid shaft. Material and geometrical parameters are given in Table 1.

Bond graph model of hydraulic system is depicted in Fig.4. Activation of 3-way direction valve is achieved using Actuator. It consists of generator of sine function and actuator which produce activation signal when amplitude of sine function becomes greater than 0.3 , as shown in Fig.5. Pump supplies the system with constant oil pressure and it is represented by source effort SE.

Applying the second Newton law leads to:

$$
(m+M) \ddot{x}=p_{1} A_{1}-p_{2} A_{2}+b \cdot \dot{x}+k \cdot x .
$$

The inertia force $(M \ddot{x})$ of the mass is developed by inertia component I, spring force $(k x)$ by capacitive component $\mathrm{C}$ and force of viscous friction $(b \dot{x})$ by $\mathrm{R}$ component.

Simulation is performed with the time step of $1 \mathrm{e}-3 \mathrm{~s}$ and simulation time of $4 \mathrm{~s}$.

To validate developed model simulation results are compared with ones obtained using MATLAB/Simulink. It is taken MATLAB/Simulink model from [10] in which values of parameters (from Tab. 1) are entered. 


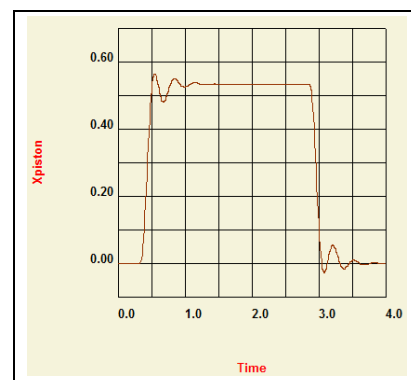

a) b)

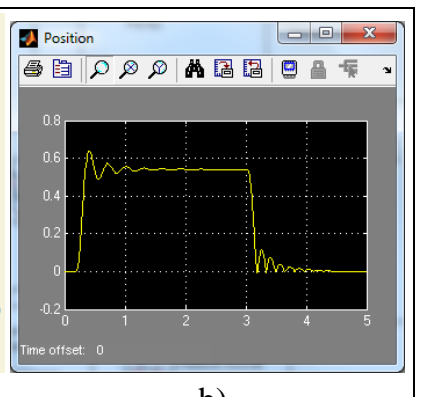

Fig. 6. The piston position obtained by a) BondSim; b) MATLAB/Simulink

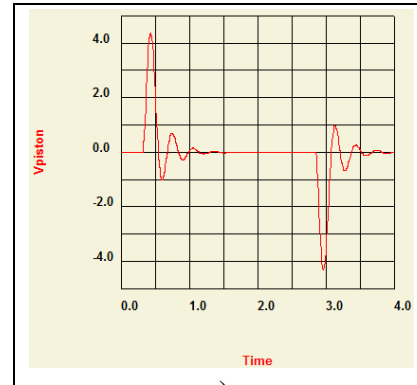

a)

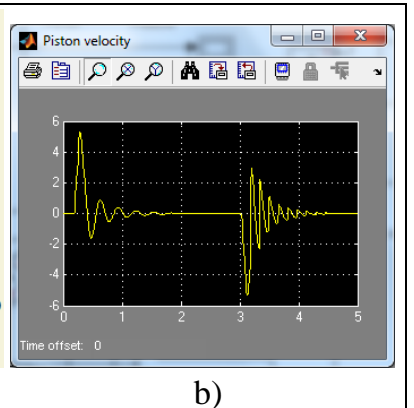

b)
Fig. 7. The piston velocity obtained by a) BondSim; b) MATLAB/Simulink

Simulation results are presented in Figs. 6-7. Results obtained by bond graph model is in good agreement with ones of MATLAB/Simulink model.

\section{CONCLUSION}

This paper presents methodology for modeling and simulation hydraulic systems, which are often used as means of power transmission in machine tools, material handling devices, mobile machines, etc. Bond graph model of hydraulic systems is developed using the program BondSim and simulation results are compared with results obtained using MATLAB/Simulink. The comparison shows good agreement. Proposed approach can be used for modeling and simulation of very complex system, which cannot be done for example using block diagrams.

The research should be extended on modeling other hydraulic components which hydraulic circuit consists of, for instance the other kind of valves (non-return, pressure limiter, etc.). In the future investigations the especially attention will be focused on analysis of different control techniques. Also, it is interested to extend the investigation to modeling of other subsystems of complex system in which hydraulic circuit is applied, for instance the mechanical part of mobile machine or mobile crane. Bond graph technique provides modeling of systems consisting of subsystems from different physical domains on the same way and can be served as powerful modeling technique.

\section{REFERENCES}

[1] Alleyne, A. \& Liu, R. (2000). A simplified approach to force control for electro-hydraulic systems, Control Engineering Practice, 8, pp.1347-1356

[2] Araya, H. \& Kagoshima, M. (2001) Semi-automatic control system for hydraulic hhovel. Automation in Construction, 10, pp.477-486
[3] Arvani, F.; Rideout, G.; Krouglicof, N. \& Butt, S. (2011). Bond Graph modeling of hydraulic vibration system: Simulation and control, Proceedings of IMAACA 2011, Sept. 28-30, 2011, Roma, Italia;

http://www.engr.mun.ca/rideout/ArvaniRideoutetal_IMAACA201 1.pdf, Accessed on: 2012-08-01

[4] Cellier, F. E. \& Nebot, A. (2005). The Modelica Bond Graph Library, The Modelica Associacion, Modelica, March 7-8, 2005. Available http://people.inf.ethz.ch/fcellier/Pubs/BG/modelica_05.pdf, Accessed: 2012-08-01

[5] Cetin, S. \& Akkaya Volkin A. (2010). Simulation and hybrid fuzzy-PID control for positioning of hydraulic system. Nonlinear Dynamic, 61, 465-476, DOI 10.1007/s11071-010-9662-1

[6] Cohodar, M.; Borutzky, W. \& Damic,V. (2009)Comparison of different formulations of 2D beam elements based on Bond Graph technique, Simulation Modelling Practice and Theory 17, pp.107124, doi:10.1016/j.simpat.2008.02.014

[7] Damic, V. \& Montgomery, J. (2003). Mechatronics by Bond Graphs, Springer-Verlag, ISBN3-540-42375-3, Berlin Heidelberg

[8] Damic,V. (2006). Modelling flexible body systems: a bond graph component model approach, Mathematical and Computer Modelling of Dynamical Systems 12, N0.2-3, pp. 175-187

[9] Guan, C. \& Pan, S. (2008). Adaptive sliding mode control of electro-hydraulic system with nonlinear unknown parameters, Conrol Engineering Practice, 16, pp.1275-1284, doi: 10.1016/j.conengpac.2008.02.002

[10] https://www.mathworks.com/products/simulink/examples.html;js essionid=b97d 367fd08fb02ba142a 7cc3abe?file=/products/demos/ shipping/simulink/sldemo_hydcyl.html, Single Hydraulic Cylinder Simulation, Accessed on: 2012-08-01

[11] Kim, W.; Won, D.; Shin, D. \& Chung, C.C. (2012). Output feedback nonlinear control for electro-hydraulic systems, Mechatronics, http:// dx.doi.org/ 10.1016/j.mechatronics.2012.03.008, Article in Press

[12] Kurniawan, A.; Pedersen, E. \& Moan, T. (2010). Bond graph modeling of a wave energy conversion system with hydraulic power take-off, poster presented at Renewable Energy Conference, Trondheim, June 7-8, 2010; Preprint submited to Elsevier, Available from: http://www.ntnu.edu/documents/174596/3697e5c5-b5ca-4e1693bc-4fba917b8383, Accessed: 2012-08-01

[13] Merritt, H.E. (1967). Hydraulic Control System, Wiley and Sons Publishers, New York

[14] Muvengei, M \& Kihiu, J. (2008). Bond Graph modeling of mechanical dynamics of an excavator for hydraulic system analysis and design. International Journal of Mechanical and Industrial Engineering, 2, 3, pp.197-205

[15] Muvengei, M \& Kihiu, J. (2011). Bond Graph modeling of interactuator interactions in multi-cylinder hydraulic system. International Journal of Aerospace and Mechanical Engineering, 5, 3, pp.147-156

[16] Papadopulos, E.; Mu, B. \& Frenette, R. (2003). On modeling, identification, and control of heavy-duty electrohydraulic harvester manipulator, IEEE/ASME Transactions on Mechatronics, Vol.8, No.2, 2003, pp.178-187, doi: 10.1109/TMECH.2003.812820

[17] Ramsebner, B. \& Rieger, K. (2009). Energy based control of hydromechanical system, Robotics and Autonomous Systems, 57, 1006-1011. doi: 10.1016/j.robot.2009.07.015

[18] Romero, G.; Felez J.; Martinez, M. L. \& del Vas, J. J. (2008). Simulation of the hydraulic circuit of a wheel loader by using the Bond Graph technique, Proceedings of $22^{\text {nd }}$ European Conference on Modelling and Simulation CECMS, June $3^{\text {rd }}-6^{\text {th }}, 2008$, Nicosia, Cyprus, ISBN 978-0-9553018-5-8, ISBN 978-09553018-6-5 (CD) Louca, L.; Chrysanthou, Y; Oplatkova, Z. \& AlBegain, K. (Ed.), Publisher, City. http://www.scseurope.net/conf/ecms2008/ecms2008\%20CD/ecms2008\%20pdf/methECMS2008_0096.pdf, Accessed on: 2012-08-01

[19] Sun, G. \& Kleeberg, M. (2003). Dynamic response of hydraulic mobile crane with considereration of the drive system, Mechanism and Machine Theory, 38, pp.1489-1508, doi: 10.1016/114X(03)00099-5

[20] Yousefi, H.; Handroos, H. \& Soleymani, A. (2008). Application of differential evolution in system identification of servo-hydrulic system with flexible load, Mechatronics, 18, pp.513-528, doi: 10.1016/mechatronics.2008.03.005 